\title{
Severe bullous diseases in the Czech Republic
}

\begin{abstract}
Bretislav Lipovy ${ }^{1 *}$, Hana Klosová2 ${ }^{2}$ Monika Tokarik³, Tomáš Kempný1 , Zuzana Chaloupková1,2, Jiř́ Štětínský2, Pavel Brychta' , Ludomír Broz ${ }^{3}$ and Zdenka Němečková Crkvenjaš²
\end{abstract}

*Correspondence: b.lipovy@seznam.cz

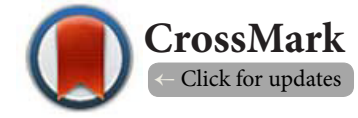

'Department of Burns and Reconstructive Surgery, University Hospital Brno, Czech Republic. ${ }^{2}$ Burn Center, University Hospital Ostrava, Czech Republic.

${ }^{3}$ Prague Burn Center, Third Faculty of Medicine, Charles University, Prague, Czech Republic.

\begin{abstract}
Aim: The study is to establish basic epidemiological characteristics of patients hospitalized in the Czech Republic with a diagnosis of toxic epidermal necrolysis (TEN) and Stevens-Johnson syndrome (SJS).

Material and methods: This is a retrospective multicenter study including hospitalized patients in the Czech Republic in the period from 1st January 1994 to 31st December 2010. The basic condition for inclusion in the study is TEN (L512) or SJS (L511) as the primary diagnosis according to International Classification of Diseases 10th version (ICD-10). The two diseases have similar clinical presentations, but have different nosological codes, which were retrieved from our database. Information was obtained from a central data depository-Department of Health Information and Statistics (National Registry of hospitalized patients).
\end{abstract}

$\underline{\text { Results: }}$ A total of 626 patients were hospitalized in our followed period. Of these, 163 patients were hospitalized with toxic epidermal necrolysis and 463 patients with Stevens-Johnson syndrome. The overall $\mathrm{M}: \mathrm{F}$ ratio in the sample was $1: 1.15$. In the group of patients with TEN M:F ratio was 1:1.31 and in the SJS group M:F ratio was 1:1.11. The mean incidence in the period in patients with TEN was $0.93 \mathrm{cases} / \mathrm{million}$ inhabitants per year. In patients with SJS, the average incidence was 2.64 cases/million inhabitants per year. The average age was 39.2 years, in patients with TEN it was 40.1 years (SD \pm 21.5$)$ and in patients with SJS 38.4 years $(\mathrm{SD} \pm 11.98)$. The average length of hospitalization was 11.3 days. In patients with TEN, the average length of hospitalization was slightly higher (11.8 days (SD \pm 3.11$)$ ) when compared with SJS group (10.7 days (SD \pm 6.48$)$ ). From the total of 626 patients, 54 patients died. Of these, it was 47 patients with TEN and 7 patients with SJS.

Conclusion: In a retrospective study confirms that SJS and TEN are rare diseases and their incidence in the Czech Republic closer to the results of most large epidemiological studies.

Keywords: Toxic epidermal necrolysis, stevens-johnson syndrome, inhabitants, Czech Republic

\section{Introduction}

Toxic epidermal necrolysis (TEN) or Lyell's syndrome is an extremely rare disease with incidence of about 0.5-2 cases/patients per 1 million inhabitants per year [1]. For yet unexplained reasons, women are more likely to be affected from this disorder. It is a potentially life-threatening toxoalergenic drug reaction that causes extensive skin and mucosal exfoliation in the junction area. The status is also complicated by systemic toxicity. Even today, many authors believe that Steven-Johnson's syndrome (SJS) is only other clinical manifestation of same immunological process as Lyell's syndrome, but causes less/smaller necrolysis of the skin and dominantly affects mucosa [2]. These syndromes together with erythema multiforme, staphylococcal scalded skin syndrome (SSSS) and pemphigus vulgaris represent a group of diseases so-called "burn-like syndromes". Lyell's syndrome is the most serious disease of this group with mortality around $40-90 \%$. It is a response to the presence of foreign antigens [3]. In $90 \%$ of patients we can find the inducing medicament that leads to development of Lyell's syndrome. The drugs with highest risk are antibiotics (trimethoprim-sulfamethoxazole, amoxicillin-clavulanic acid), followed by NSAIDs, anticonvulsants (carbamazepine, valproate), allopurinol, corticosteroids, 
Lipovy et al. Epidemiology Reports 2014,

antidepressants, anxiolytics, etc. However, in more than $10 \%$ cases the cause remains unknown [4].

Most commonly affected patients are aged $40-60$ years, while older people may have a relatively higher risk of developing this disease, because they use more medication/drugs. The incidence of Lyell's syndrome is frequently observed in patients after bone marrow transplantation and in HIVpositive patients [5].

For successful treatment and better survival of affected patients it is essential to comply with certain principles. Particularly important is early diagnosis and prompt therapy, avoiding any unnecessary medications. Accurate microbiological surveillance is the most important part of the therapy, because the main cause of mortality in patients with TEN are infectious complications. Typical agents causing infectious complications in patients with TEN and SJS include not only bacteria such as Pseudomonas aeruginosa, Acinetobacter baumannii, Coagulasa negat. Staphylococcus, Staphylococcus aureus (methicillin-sensitive or methicilin resistant), but also yeasts and fungi [6].

The main objective of this study is to describe the basic epidemiological parameters of patients hospitalized with Lyell's and Stevens-Johnson's syndrome in the Czech Republic in the period 1994-2010.

\section{Material and methods}

This is a retrospective multicenter study conducted on hospitalized patients in the Czech Republic in the period from $1^{\text {st }}$ January 1994 to $31^{\text {st }}$ December 2010. The basic condition for inclusion to the study is the primary diagnosis Toxic epidermal necrolysis (L512) or Stevens-Johnson syndrome (L511) according to ICD-10. Clinical differentiation of syndromes is based mainly on the extent of exfoliating surface. Czech Republic is a country in Central Europe, the population ranges over the period from $10,333 \times 10^{3}$ in 1994 to $10,532 \times 10^{3}$ in 2010 . The dominant role in the treatment of severe bullous disease in the Czech Republic play three burn centers. The largest burn center is in Prague, another is in Ostrava and in Brno. Furthermore, patients with burn-like syndromes are also treated in large hospitals (university type), and the minority is treated on dermatological units of smaller hospitals.

Information was obtained from a central data depositoryDepartment of Health Information and Statistics (National Register of hospitalized patients). The results were then compared with data from individual burn centers. Population in the Czech Republic is determined through census and natality and mortality calculations every year. These calculations are performed by the Czech Statistical Office.

In all patients with diagnose Toxic epidermal necrolysis and Stevens-Johnson's syndrome were studied basic epidemiological indicators such as gender, age, length of hospitalization and mortality.

\section{Results}

In total, 626 patients were hospitalized with the diagnose L511 and L512 according to ICD-10 in the period. Of these, 163 patients were hospitalized (26.0\%) with Toxic epidermal necrolysis and 463 patients with Stevens-Johnson's syndrome. The number of reported patient hospitalizations with TEN and SJS in individual/each years in the period is shown in Figure 1 below. Only 43 patients (26.4\%) with TEN, and 29 patients $(6.3 \%)$ with SJS were hospitalized in burn centers in the Czech Republic.

Of the 626 patients hospitalized in the period, 335 were

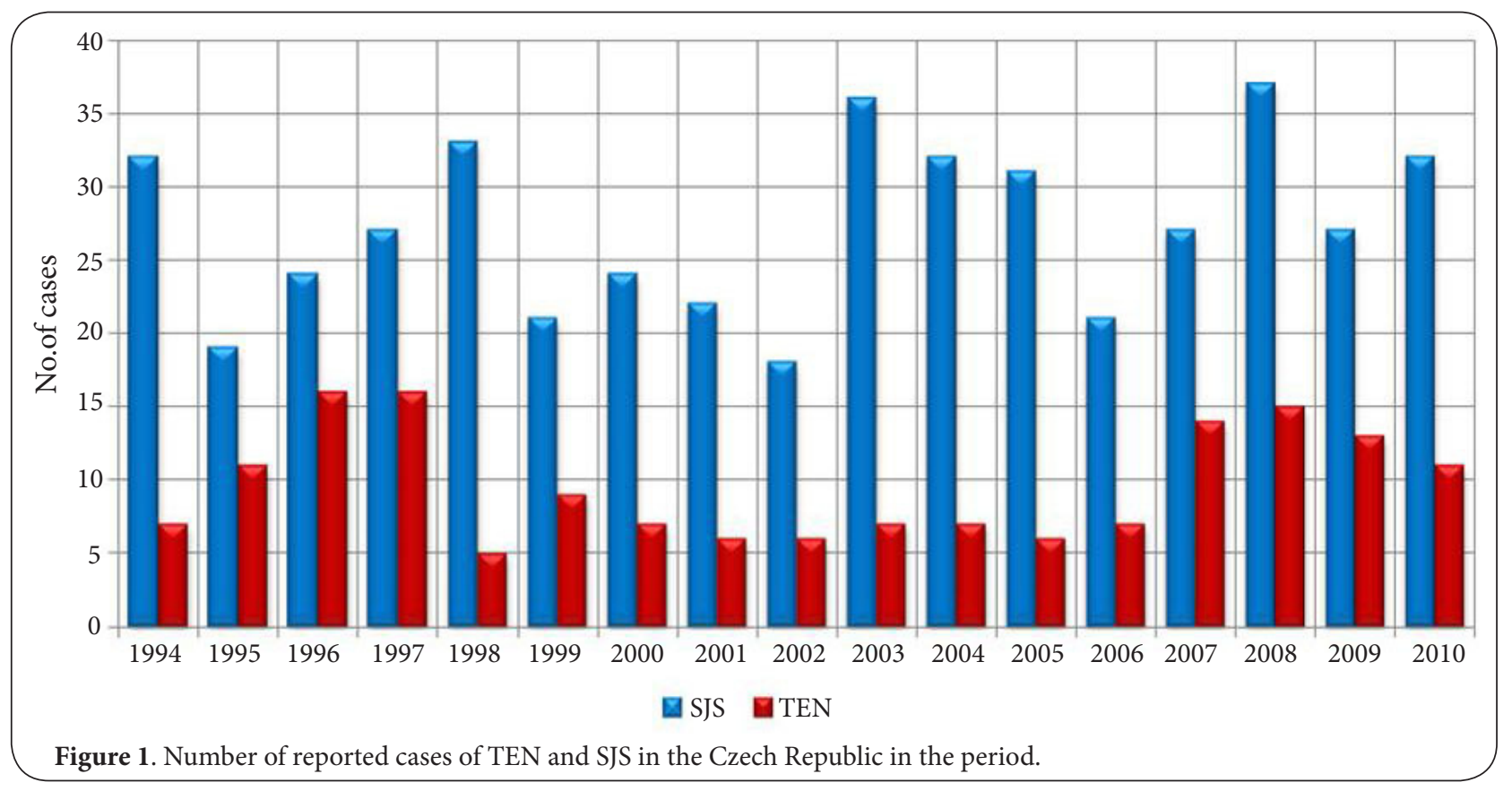


women and 291 men. The overall M:F ratio in the group was 1:1.15. In the group of patients with TEN the M:F ratio was 1:1.31 and in the SJS group it was 1:1.11. The sex ratio for each year of the period in patients with TEN and SJS illustrates Figures 2 and 3.

The average incidence in the period in patients with TEN was at the value of 0.93 cases/million inhabitants per year. The highest incidence was recorded in 1996-1997 (1.55 cases/ million inhabitants per year), while the lowest incidence was in 1998 ( 0.49 cases/million inhabitants and year). In patients with SJS, the average incidence was 2.64 cases/million inhabit- ants and year, the highest incidence was found in 2008 (3.54 cases/million inhabitants and year), the lowest in 2002 (1.76 cases/million inhabitants and year). The incidence of SJS and TEN in the Czech Republic in the period is shown in Table 1.

The average age was 39.2 years, in patients with TEN 40.1 years (SD \pm 21.5$)$ and in patients with SJS 38.4 years (SD \pm 11.98 ). The difference is recorded in the average age of hospitalized men (31 years in TEN (SD \pm 16.63$)$ and 34.2 years in SJS $(S D \pm 14.24)$ ) and women (46 years in TEN (SD \pm 15.78$)$ and 42.3 years in SJS (SD \pm 10.72$)$ ). The average age of patients with TEN and SJS in individual years of the period is shown in Figure 4.
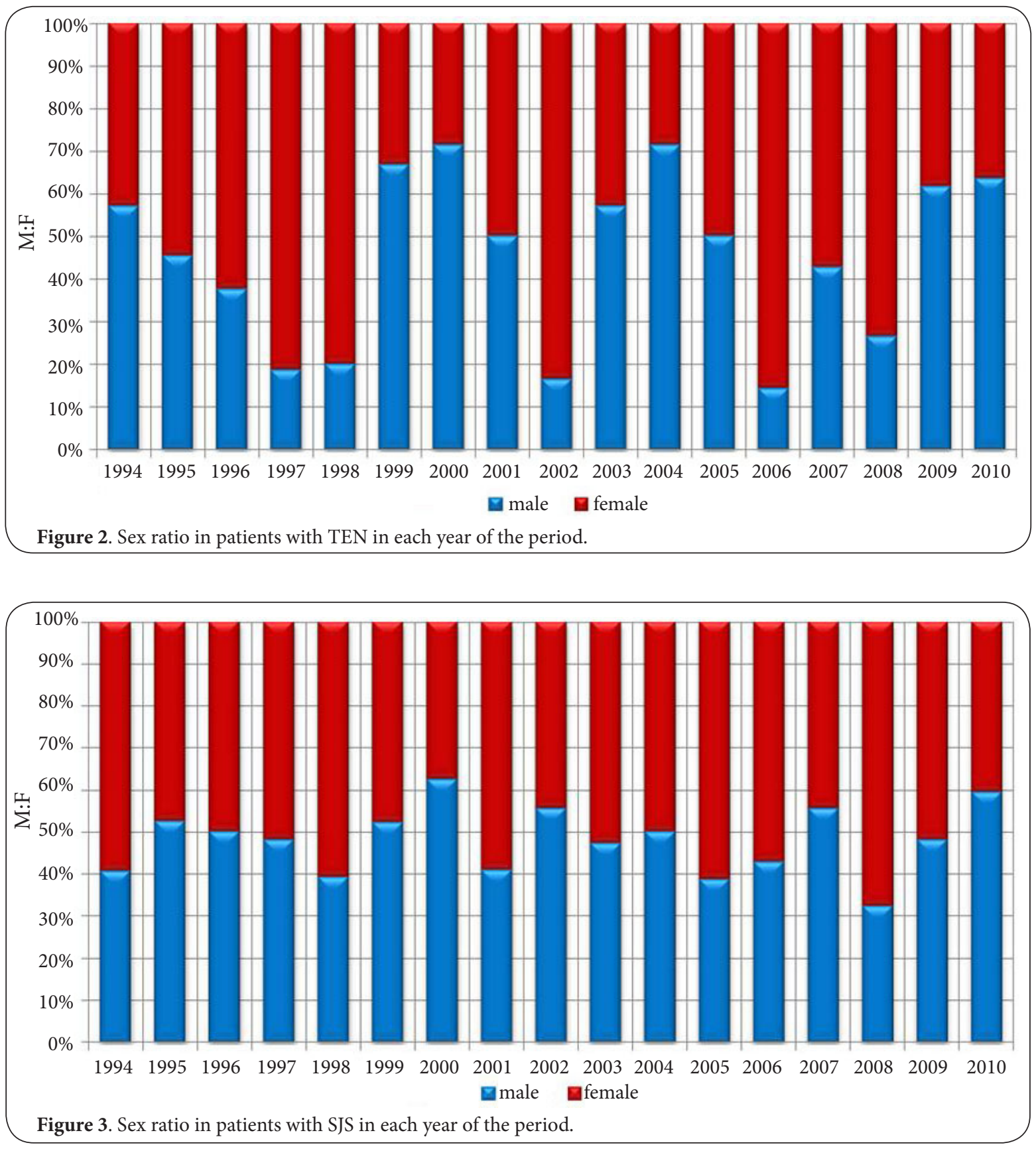
Lipovy et al. Epidemiology Reports 2014,

http://www.hoajonline.com/journals/pdf/2054-9911-2-5.pdf

doi: 10.7243/2054-9911-2-5

Table 1. Number of patients with TEN and SJS and TEN and SJS incidence in each year of the period.

\begin{tabular}{llllll}
\hline Year & Populationx10 & $\begin{array}{l}\text { Patients } \\
\text { with SJS }\end{array}$ & $\begin{array}{l}\text { Incidence of SJS } \\
\text { x/1 mil inhabitants }\end{array}$ & $\begin{array}{l}\text { Patients } \\
\text { with TEN }\end{array}$ & $\begin{array}{l}\text { Incidence of TEN } \\
\text { x/1 mil inhabitants }\end{array}$ \\
\hline 1994 & 10333 & 32 & 3.10 & 7 & 0.68 \\
1995 & 10321 & 19 & 1.84 & 11 & 1.07 \\
1996 & 10309 & 24 & 2.33 & 16 & 1.55 \\
1997 & 10299 & 27 & 2.62 & 16 & 1.55 \\
1998 & 10290 & 33 & 3.21 & 5 & 0.49 \\
1999 & 10278 & 21 & 2.04 & 9 & 0.88 \\
2000 & 10267 & 24 & 2.34 & 7 & 0.68 \\
2001 & 10206 & 22 & 2.16 & 6 & 0.59 \\
2002 & 10203 & 18 & 1.76 & 6 & 0.59 \\
2003 & 10211 & 36 & 3.53 & 7 & 0.69 \\
2004 & 10221 & 32 & 3.13 & 7 & 0.69 \\
2005 & 10251 & 31 & 3.02 & 6 & 0.59 \\
2006 & 10287 & 21 & 2.04 & 7 & 0.68 \\
2007 & 10381 & 27 & 2.60 & 14 & 1.35 \\
2008 & 10468 & 37 & 3.54 & 15 & 1.43 \\
2009 & 10507 & 27 & 2.57 & 13 & 1.24 \\
2010 & 10532 & 32 & 3.04 & 11 & 1.04 \\
$\varnothing$ & 10316 & 27.2 & 2.64 & 9.6 & 0.93 \\
\hline
\end{tabular}

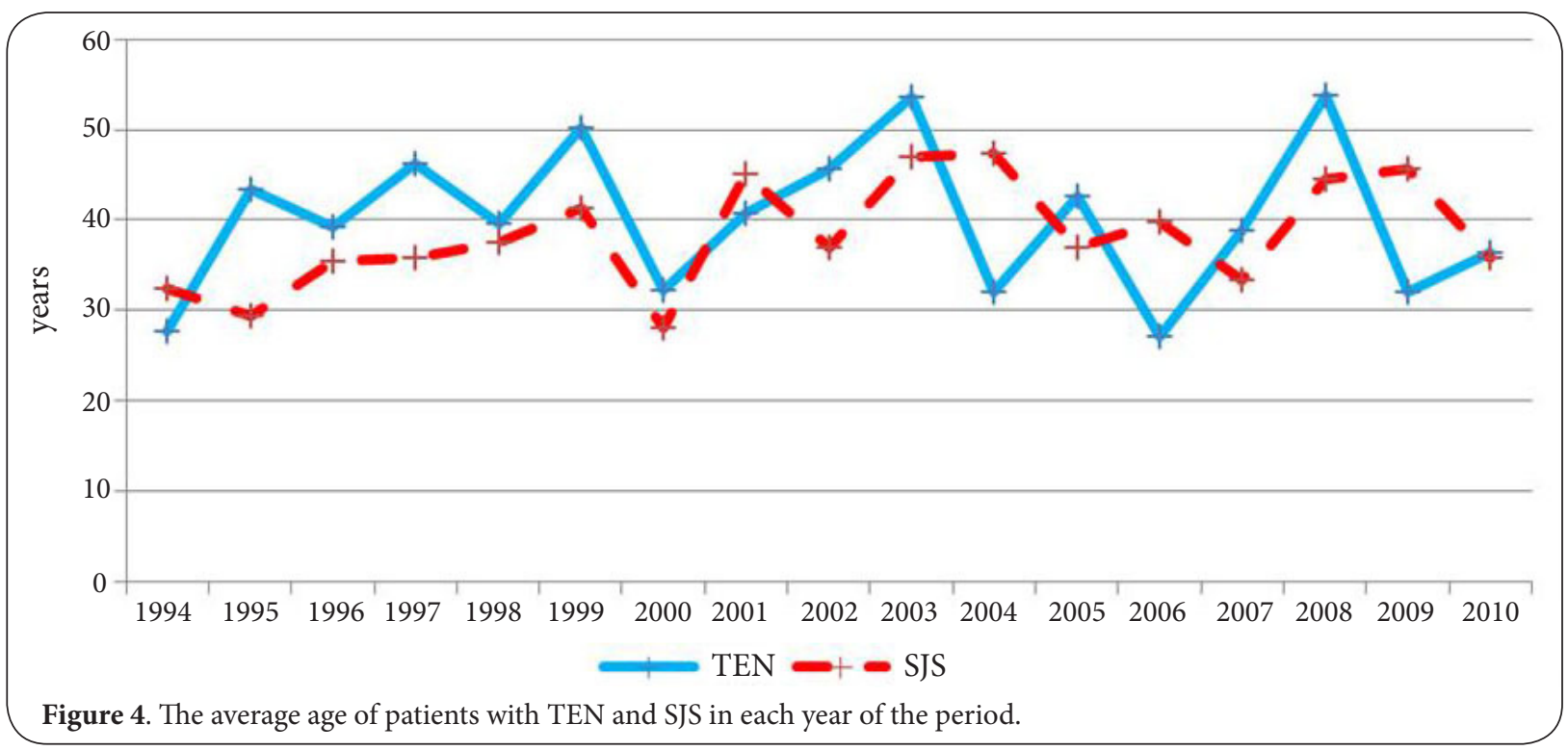

The influence of various drugs on the development of TEN in the study was monitored and evaluated according to data from individual burn centers [7]. The cause of the development of TEN has been identified in a total of 43 patients. In remaining patients the etiology could not be traced or clearly defined. The most common etiological agents were antibiotics (in 19 patients) and AEDs (in 9 patients). The representation of different groups of drugs in the patient population is shown in Figure 5.

The average length of hospitalization for all patients was 11.3 days. In patients with TEN, the average length of hospitaliza- tion was slightly higher (11.8 days (SD \pm 3.11$)$ ) when compared with SJS group (10.7 days (SD \pm 6.48$)$ ). The difference is also observed in the length of hospitalization among men and women. In TEN, the average length of hospitalization was 10.0 days (SD \pm 4.27 ) for men and 14.1 days $(S D \pm 5.21)$ for women. By contrast, in the case of SJS the length of hospitalization was virtually identical without sexual preference, 10.5 days $(S D \pm 5.35)$ for men and 10.9 days $(S D \pm 4.62)$ for women. The average length of hospitalization in patients with TEN and SJS is shown in Figure 6.

Of the 626 patients, 54 patients died. The overall mortality 

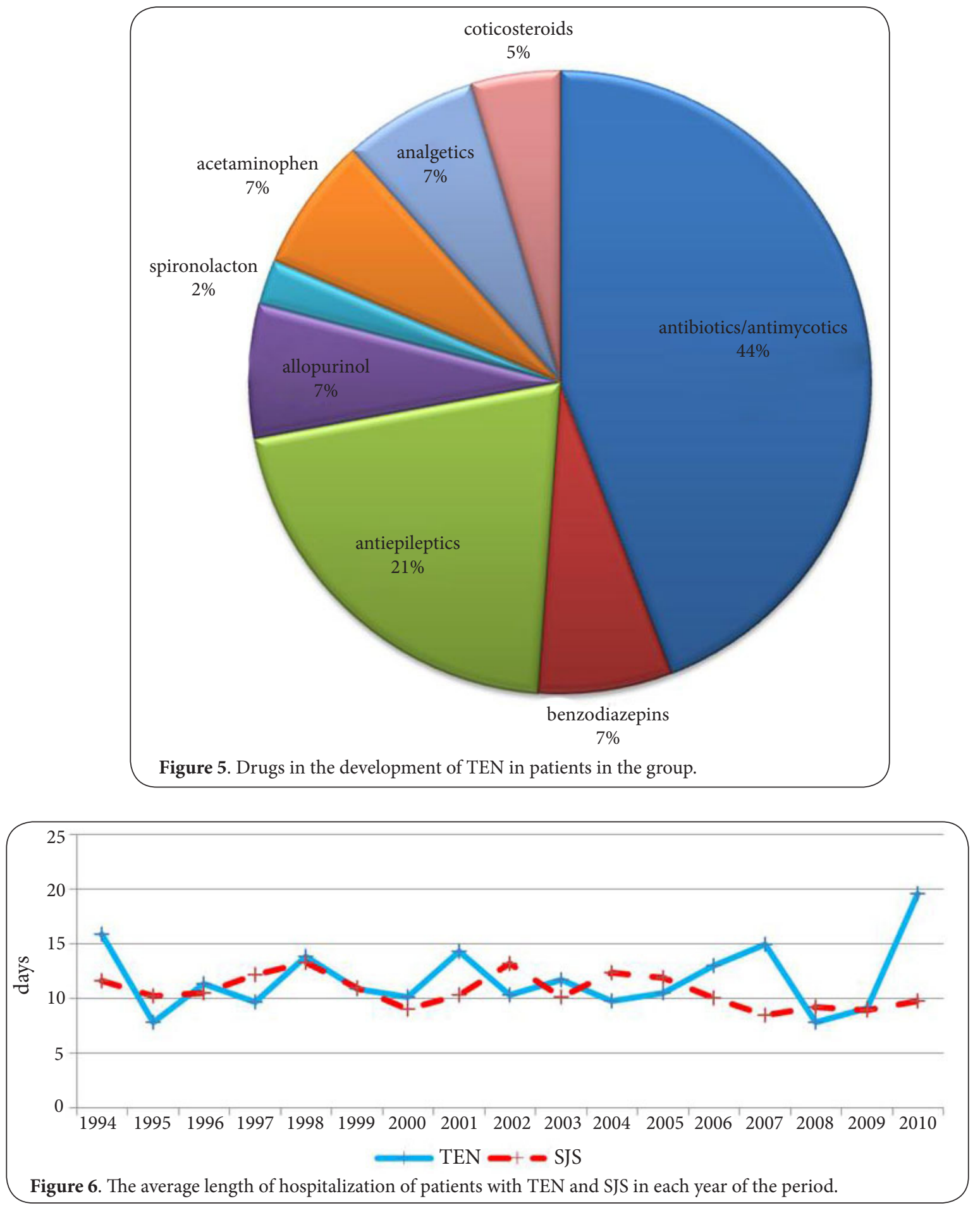

was $8.62 \%$. Of these, 47 patients died with TEN and 7 patients with SJS. The mortality in patients with TEN was $33.13 \%$ and in patients with SJS it was $1.51 \%$. Mortality in the period in patients with TEN and SJS is shown in Figure 7.

\section{Discussion}

TEN and SJS are very rare bullous diseases that may have a lethal impact on the patient. In particular, in patients with TEN mortality is still very high. Significant changes in mortality and length of hospital stay in each year of the period are caused mainly due to the small number of patients in the study group. This reality causes a relatively large variation in the incidence of TEN and SJS, but also in mortality and length of hospital stay. 


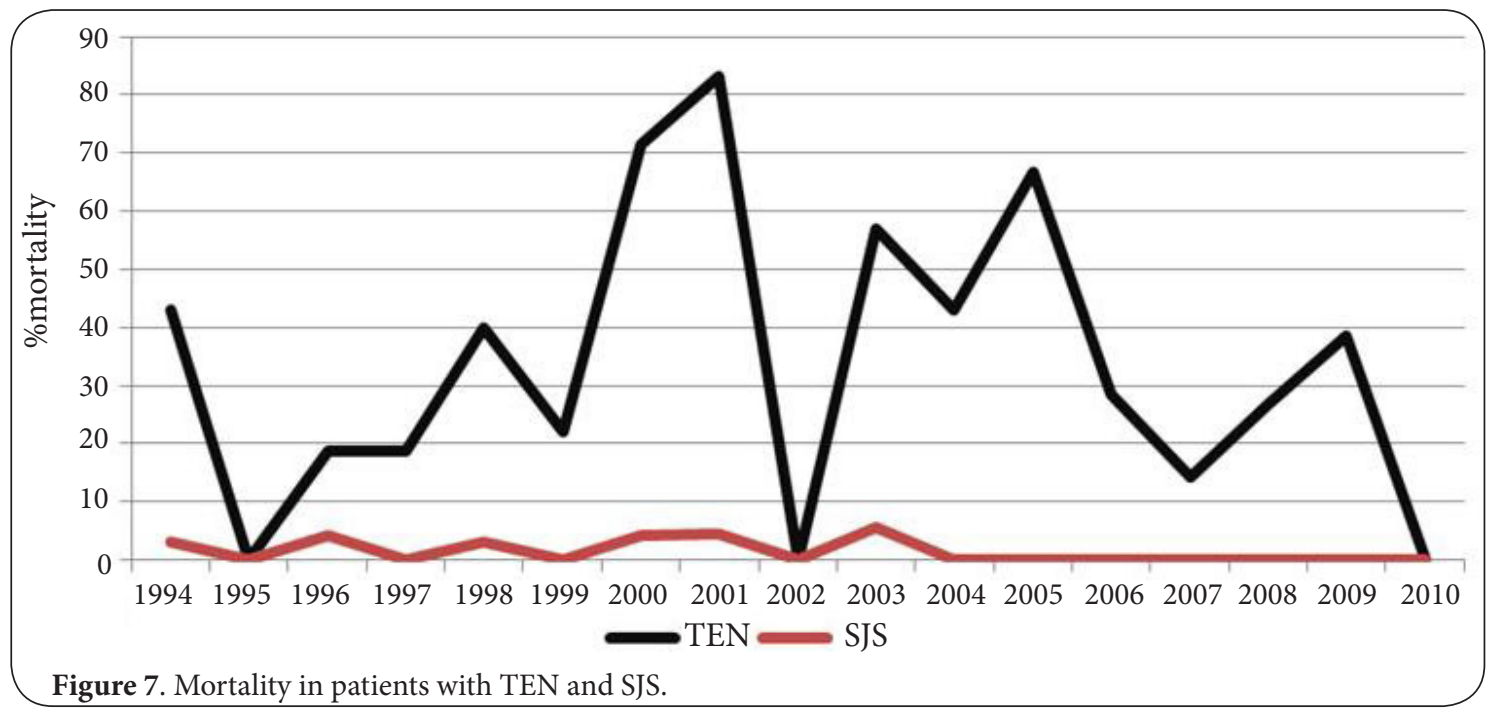

The healing of skin defect itself must be as prompt as possible, because every exfoliation area has a potential for complete spontaneous healing [8]. Here, the factor of time is very important. The protracted healing increases the risk of infection of the exfoliation area, resulting in a slowdown of the process of wound healing or in deepening the defect, which may subsequently lose its spontaneous potential for re-epithelization [9]. In patients with TEN (with extensive skin or mucosa exfoliation over $30 \%$ TBSA (total body surface area) is for the survival absolutely essential to give adequate local intravenous systemic therapy in the shortest period after the development of the first symptoms. The treatment of affected patients should always be in a specialized burn center, which allows optimal and adequate therapy management of patients with SJS or TEN. But yet, the transfer of patients to specialized centers is still a significant problem worldwide. So patients do not get adequate treatment in time. In 1999, Sheridan et al., published a work focusing on the timeliness of transfer of a patient with TEN to a specialized center [10]. The average time in his study was 6.6 days. A similar result was published in the work of Ying et al., where the average time for transfer to a burn center was 6.1 days [11]. By contrast, in a study Khoo et al., published data, that declared a period of only 4.1 days [12]. This study included only 7 patients. In this respect, the Czech Republic has a considerable advantage, which is given by the geography of individual burn centers and their cooperation. This facilitates the transfer of affected patients in the burn center.

The average length of hospitalization in patients with TEN in our patient group was 11.8 days. Momin and Moniz show a similar average length of hospitalization, 12.5 days, 12.6 days respectively $[13,14]$. Conversely Khoo et al., describe in their study of patients with TEN mean duration of hospitalization of 34.1 days [12]. Higher average length of hospitalization were also observed in a study of Levi et al., in this study, 80 cases of patients with SJS and TEN were studied, and the average length of hospital stay was 17 days [15].

Large epidemiological studies indicate more frequent occurrence of SJS and TEN in women. Yet, there have not been published reliable data that would support and explain the pathophysiological basis of this statement. Also in our study, we record more frequent occurrence of TEN and SJS in women. Sexual preference is more pronounced in the case of TEN, where the M:F ratio is 1:1.31. Far larger sex differences recorded Khoo et al., in his study, where from 23 patients with TEN, a total of 16 were women [12]. Brand et al., achieved in his work M:F ratio 1:2 in 12 patients with TEN [16].

The incidence of TEN has been reported worldwide in all age groups. Yet there are groups such as immunocompromised patients, who suffer more often. It is said that in Europe is about $5 \%$ of patients with TEN after bone marrow transplantation or suffering AIDS. The average incidence of SJS and TEN is in absolute correlation with the most world's epidemiological studies. The incidence for TEN ranges in large epidemiological surveys from 0.4 to 1.2 cases per million population per year. It is slightly higher in SJS (1-6 cases per million population per year). The study of Ventura et al., shows the incidence of TEN in the range of 1.17-1.89 cases per million population per year [17]. Li et al., shows the incidence of TEN of only 0.05 cases per million population per year and in the case of SJS 0.8 cases per million inhabitants per year [18]. The publications from France and Germany show that the incidence of TEN in the population has not changed much over the past 30 years (the incidence was $0.93-1.3$ cases per million population per year) [19-21].

The average age in our group of patients with TEN was 40.1 years and in patients with SJS 38.4 years. For men, the mean age was 31.0 years and for women it was 46.0 . In the Australian study, the mean age was 50.7 years [16]. In contrast to our study, the average age of women was less than of men (44.9 years, 62.2 years). Already in 1967 Lyell published a set of 128 patients with TEN, in which mortality was 30\% [22] 
Most epidemiological studies then have mortality around 10-35\%. Especially in large epidemiological studies that were published at the beginning of the 90 s of the last century mortality is $30 \%$ resp. $34 \%[20,23]$. Data in our study show $33.13 \%$ mortality. In a study of SJS and TEN epidemiology in developing countries, Ugburo et al., shows the mortality for TEN 60\% [24]. However, this study included only 5 patients. On the contrary, all 6 patients with SJS survived. High mortality ratio (50\%) also describes in his study that included 20 patients Moniz et al [14].

\section{Conclusion}

For a selected group of patients, we were able to define basic epidemiological data. Our retrospective study confirms that SJS and TEN are rare diseases and that their incidence and etiology in the Czech Republic confirm the results of most published studies.

\section{Competing interests}

The authors declare that they have no competing interests.

Authors' contributions

\begin{tabular}{|l|c|c|c|c|c|c|c|c|c|}
\hline Authors' contributions & BL & HK & MT & TK & ZC & JS & PB & LB & ZNC \\
\hline $\begin{array}{l}\text { Research concept and } \\
\text { design }\end{array}$ & $\checkmark$ & $\checkmark$ & $\checkmark$ & -- & -- & $\checkmark$ & -- & $\checkmark$ & $\checkmark$ \\
\hline $\begin{array}{l}\text { Collection and/or } \\
\text { assembly of data }\end{array}$ & $\checkmark$ & $\checkmark$ & $\checkmark$ & -- & -- & $\checkmark$ & -- & -- & -- \\
\hline $\begin{array}{l}\text { Data analysis and } \\
\text { interpretation }\end{array}$ & $\checkmark$ & $\checkmark$ & $\checkmark$ & -- & -- & $\checkmark$ & -- & -- & -- \\
\hline Writing the article & $\checkmark$ & -- & -- & $\checkmark$ & $\checkmark$ & -- & -- & -- & -- \\
\hline $\begin{array}{l}\text { Critical revision of the } \\
\text { article }\end{array}$ & -- & -- & -- & $\checkmark$ & $\checkmark$ & -- & $\checkmark$ & -- & - \\
\hline Final approval of article & $\checkmark$ & -- & -- & $\checkmark$ & -- & -- & -- & -- & -- \\
\hline Statistical analysis & $\checkmark$ & -- & -- & $\checkmark$ & -- & -- & -- & -- & -- \\
\hline
\end{tabular}

Publication history

Editor: Nicola Luigi Bagazzi, University of Genoa, Italy.

Received: 17-Aug-2014 Final Revised: 06-Nov-2014

Accepted: 20-Nov-2014 Published: 27-Nov-2014

\section{References}

1. Becker DS. Toxic epidermal necrolysis. Lancet. 1998; 351:1417-20. | Article I PubMed

2. Murphy JT, Purdue GF and Hunt JL. Toxic epidermal necrolysis. J Burn Care Rehabil. 1997; 18:417-20. I PubMed

3. Chave TA, Mortimer NJ, Sladden MJ, Hall AP and Hutchinson PE. Toxic epidermal necrolysis: current evidence, practical management and future directions. Br J Dermatol. 2005; 153:241-53. I Article I PubMed

4. Revuz J, Penso D, Roujeau JC, Guillaume JC, Payne CR, Wechsler J and Touraine R. Toxic epidermal necrolysis. Clinical findings and prognosis factors in 87 patients. Arch Dermatol. 1987; 123:1160-5. | Article | PubMed

5. Saiag P, Caumes E, Chosidow O, Revuz J and Roujeau JC. Drug-induced toxic epidermal necrolysis (Lyell syndrome) in patients infected with the human immunodeficiency virus. J Am Acad Dermatol. 1992; 26:567-74. | Article | PubMed

6. Pasricha JS, Khaitan BK, Shantharaman R, Mital A and Girdhar M. Toxic epidermal necrolysis. Int J Dermatol. 1996; 35:523-7. | $\underline{\text { Article | PubMed }}$

7. Zajicek R, Pintar D, Broz L, Suca H and Konigova R. Toxic epidermal necrolysis and Stevens-Johnson syndrome at the Prague Burn Centre 1998-2008. J Eur Acad Dermatol Venereol. 2012; 26:639-43. | Article | PubMed

8. Paquet P, Pierard GE and Quatresooz P. Novel treatments for druginduced toxic epidermal necrolysis (Lyell's syndrome). Int Arch Allergy Immunol. 2005; 136:205-16. | Article | PubMed

9. Halebian PH and Shires GT. Burn unit treatment of acute, severe

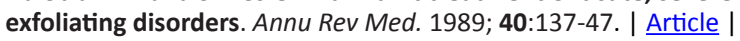
PubMed

10. Sheridan RL, Weber JM, Schulz JT, Ryan CM, Low HM and Tompkins RG. Management of severe toxic epidermal necrolysis in children. J Burn Care Rehabil. 1999; 20:497-500. I PubMed

11. Ying S, Ho W and Chan HH. Toxic epidermal necrolysis: 10 years experience of a burns centre in Hong Kong. Burns. 2001; 27:372-5. I Article | PubMed

12. Khoo AK and Foo CL. Toxic epidermal necrolysis in a burns centre: a 6-year review. Burns. 1996; 22:275-8. I Article I PubMed

13. Momin SB. Review of intravenous immunoglobulin in the treatment of stevens-johnson syndrome and toxic epidermal necrolysis. J Clin Aesthet Dermatol. 2009; 2:51-8. | PubMed Abstract | PubMed Full Text

14. Moniz P, Casal D, Mavioso C, Castro JV and Almeida MA. [StevensJohnson syndrome and toxic epidermal necrolysis: a 15-year retrospective study]. Acta Med Port. 2011; 24:59-70. | PubMed

15. Levi N, Bastuji-Garin S, Mockenhaupt M, Roujeau JC, Flahault A, Kelly JP, Martin E, Kaufman DW and Maison P. Medications as risk factors of Stevens-Johnson syndrome and toxic epidermal necrolysis in children: a pooled analysis. Pediatrics. 2009; 123:297-304. I Article I PubMed

16. Brand R and Rohr JB. Toxic epidermal necrolysis in Western Australia. Australas J Dermatol. 2000; 41:31-3. I Article I PubMed

17. Ventura F, Fracasso T, Leoncini A, Gentile R and de Stefano F. Death caused by toxic epidermal necrolysis (Lyell syndrome). J Forensic Sci. 2010; 55:839-41. | Article | PubMed

18. Li LF and Ma C. Epidemiological study of severe cutaneous adverse drug reactions in a city district of China. Clin Exp Dermatol. 2006; 31:642-7. | Article I PubMed

19. Mockenhaupt M, Viboud C, Dunant A, Naldi L, Halevy S, Bouwes Bavinck JN, Sidoroff A, Schneck J, Roujeau JC and Flahault A. Stevens-Johnson syndrome and toxic epidermal necrolysis: assessment of medication risks with emphasis on recently marketed drugs. The EuroSCAR-study. J Invest Dermatol. 2008; 128:35-44. | Article | PubMed

20. Roujeau JC, Kelly JP, Naldi L, Rzany B, Stern RS, Anderson T, Auquier A, Bastuji-Garin S, Correia O, Locati F and et al. Medication use and the risk of Stevens-Johnson syndrome or toxic epidermal necrolysis. $N$ Engl J Med. 1995; 333:1600-7. I Article I PubMed

21. Mockenhaupt M. Epidemiology of cutaneous adverse drug reactions. Chem Immunol Allergy. 2012; 97:1-17. | Article | PubMed

22. Lyell A. A review of toxic epidermal necrolysis in Britain. Br J Dermatol. 1967; 79:662-71. I Article I PubMed

23. Lyell A. Drug-induced toxic epidermal necrolysis. I. An overview. Clin Dermatol. 1993; 11:491-2. I Article I PubMed

24. Ugburo AO, Temiye EO and Ilombu CA. A 12-year retrospective study of non-burn skin loss (burn-like syndromes) at a tertiary burns unit in a developing country. Burns. 2008; 34:637-43. | Article I PubMed

\section{Citation:}

Lipovy B, Klosová H, Tokarik M, Kempný T, Chaloupková Z, Štětínský J, Brychta P, BroBroz L and Crkvenjaš ZN. Severe bullous diseases in the Czech Republic. Epidemiol Rep. 2014; 2:5.

http://dx.doi.org/10.7243/2054-9911-2-5 